\title{
Mathematical modelling of the elastic behavior of structured geophysical media
}

\author{
(C) N. V. Olali ${ }^{1}$, D. B. Vengrovich ${ }^{2}$, M. P. Malezhyk ${ }^{3}, 2017$ \\ ${ }^{1}$ Niger Delta University, Wilberforce Island Bayelsa State, Bayelsa, Nigeria \\ ${ }^{2}$ Institute of Geophysics, National Academy of Sciences of Ukraine, Kiev, Ukraine \\ ${ }^{3}$ Dragomanov National Pedagogical University, Kyiv, Ukraine
}

Received 6 October 2017

\begin{abstract}
3 точки зору сучасної нелінійної геофізики неоднорідність, наявність ісрархічної блокової структури, анізотропія $\epsilon$ визначальними властивостями природного середовища, зокрема земної кори. Багато досягнень сучасної теорії самоорганізації в геофізиці грунтуються на вже споруджуваних базових моделях структурованих середовищ. Структура грас ключову роль в динаміці земної кори, вона має велике значення для виникнення тектонічних напружень, їх локалізації і наступних процесів їх вивільнення. Як показано в роботі [Старостенко и др., 2001], такі структуровані середовища необхідно описати на мікро-, мезо- і макрорівнях у рамках моделей взасмодіючих блоків, які дозволяють достовірно описати такі тектонічні процеси, як формування і еволюція рифтових осадових басейнів, стиснення земної кори в зонах субдукції [Венгрович 2017], соляну тектоніку [Венгрович, 2010]. Використовувані підходи для розрахунку динаміки величезного числа взаємодіючих блоків дуже затратні. Запропоновано математичну модель пружної поведінки структурованого геофізичного середовища, що дозволяє в певних випадках отримати аналітичні залежності між їі пружними параметрами і структурою. Середовище описано в першому наближенні твердою матрицею 3 включенням гранул 3 іншими реологічними властивостями. Представлені чисельні (модель МСE) і аналітичні розрахунки полів напружень в реальних середовищах для моделей 3 внутрішньою періодичною структурою, порівняння яких підтверджує пирокі межі застосування запропонованої аналітичної моделі.
\end{abstract}

Ключові слова: поля напружень, геофізичні середовища, структура, кора, модулі пружності.

Environment structure. We will consider the process of quasi-static elastic deformation of an inhomogeneous medium to get the values of the elastic constants of this material. Now suppose that such an environment is a matrix of 3D regularly arranged granules and the spaces between those are filled with another substance. In such a case the model structure will be built based on the translation and rotation symmetry of the regular environment with the equal particles. The distribution of the particle centers in the space will be presented as a sequence of spatial lattice vectors [Lure, 1955]. The simplest structure of this type is created by infinite set of parallelepipeds, which angular points are determined by the vector $\mathbf{e}=\mathbf{e}_{1} m \omega_{1}+\mathbf{e}_{2} n \omega_{2}+\mathbf{e}_{3} p \omega_{3}$ where $\mathbf{e}_{k}(k=1,2,3)$ are the unit vectors directed along the parallelepiped sides; $m, n, p$ - the set of natural numbers; $\omega_{k}(k=1,2,3)$ - the parallelepiped period lengths. In the more complex structures there is a group of inclusions near each angular point of the spatial lattice. This fact leads to different structures and symmetry groups.

For a first approximation the theory of effective modules of elasticity is based on determining the relative volumetric filling of environment with particles $\zeta$, and also depends on the type of balls packing and cyclic symmetry in the structure. In the regular structure the first and the second parameters $\omega_{k}$ determine the mutual distance from the edge to the edge allowing to assess their interaction from extinction of function; the last determines symmetry in tension, which is required when selecting the type of functions that determines this state. The simplest cubic lattice $\omega_{1}=\omega_{2}=\omega_{3}=\omega$ is a cube in the angles of which 
there are centers of identical balls (Fig. 1,a). The volume of one cell includes one eighth part of volume of each ball in the grid node. It means that there is one ball in the cell. A limit volume filling takes place for dense packing of balls with the radius when the spheres touch each other $\omega=2 a$ :

$$
\zeta=\frac{4 \pi a^{3}}{3 \omega^{3}}=\frac{\pi}{6} \approx 0,52 .
$$

The stress condition in such structure will be determined by cyclic symmetry in three mutually perpendicular planes with angle period $\alpha=\pi / 4$. If we put another sphere in the center of cubic structure there will be two balls in the one cell, so dense packing takes place when the balls touch each other on the diagonal of the cube. The extreme dimensions are determined by the ratio $(4 a)^{2}=\omega^{2}+(\omega \sqrt{2})^{2}$, $a=\sqrt{3} / 4$, extreme volume fraction:

$$
\zeta=\frac{8 \pi a^{3}}{3 \omega^{3}}=\frac{\sqrt{3} \pi}{8} \approx 0,68 .
$$

In such body-centered cubic structure the cyclic symmetry will be also determined by the inclination

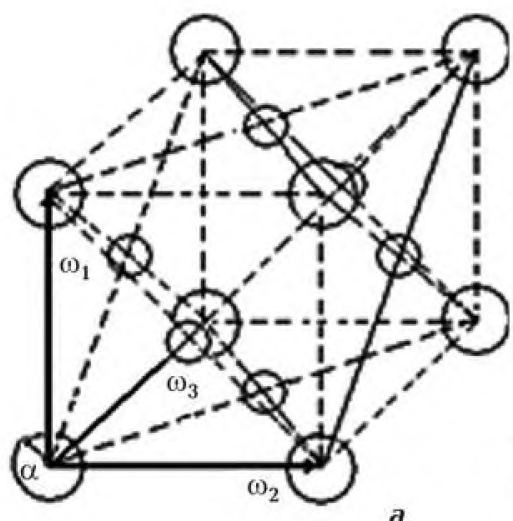

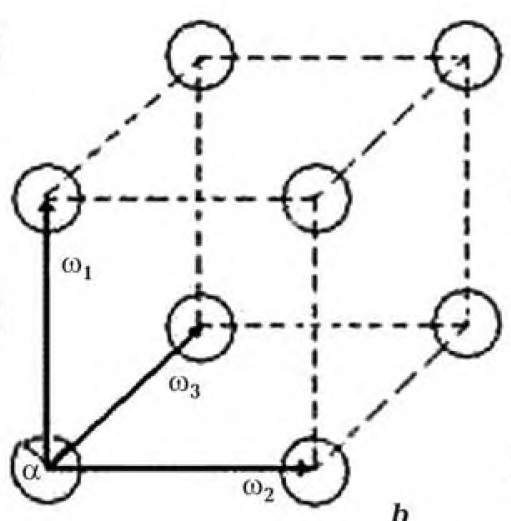

$b$
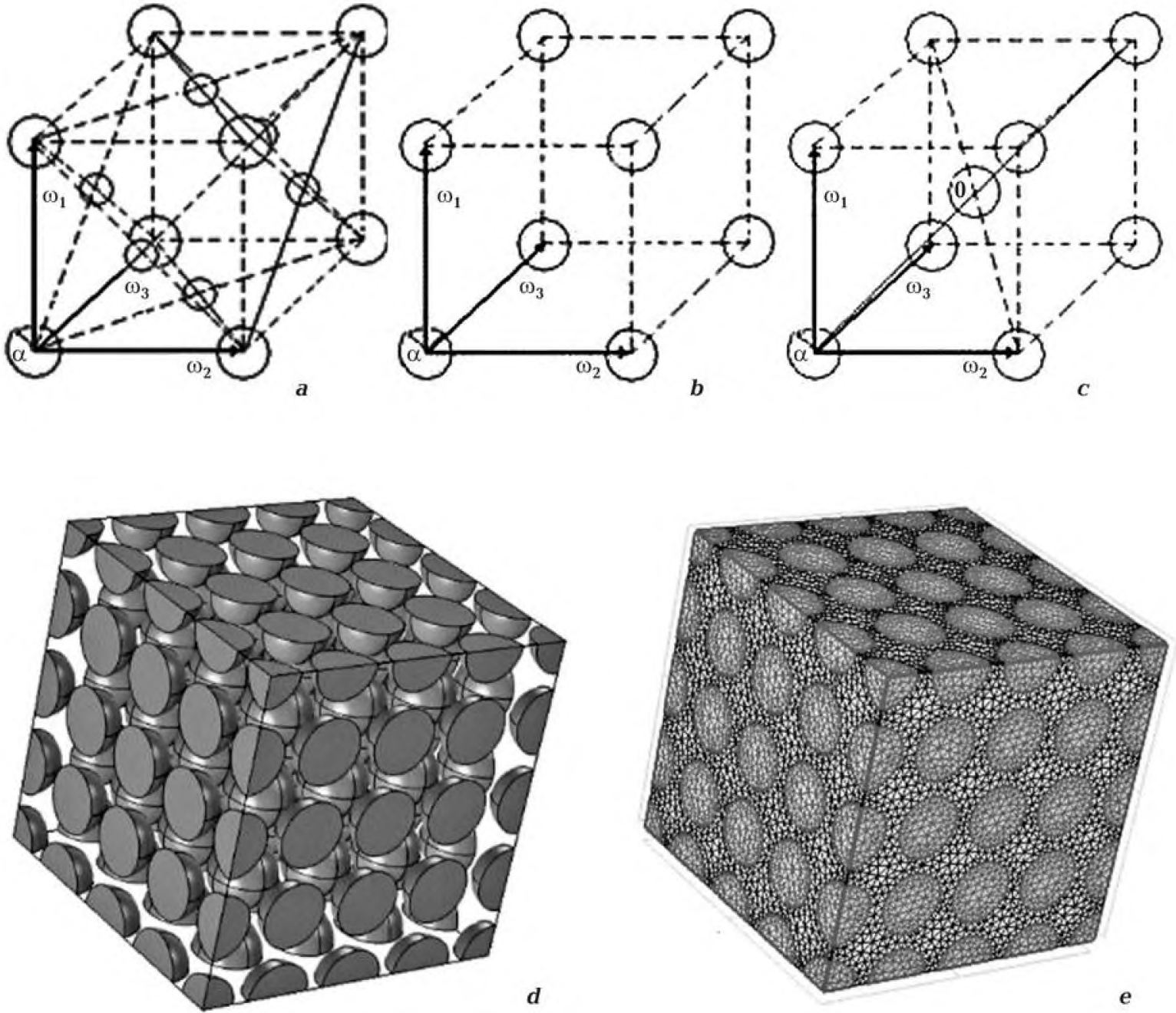

Fig. 1. Cubic lattice with different filled density: $a$ - simple lattice, $b$ - body-centered lattice, $c-$ side-centered lattice, $d$ - numerical Finite Element Model implementation of the medium, the boundary reflection symmetric conditions are applied on the cube faces, $e$ - finite element mesh used in calculation. 
of plane of the lattice symmetry according to this fact the angle period will be changed. If we put additional ball in each cube face in the cubic structure, this cell includes the half of their volume (Fig. 1). There will be only four inclusions in the selected volume: $4 a^{2}=2 \omega^{2}, a=\omega \frac{\sqrt{2}}{4}$.

The most volumetric filling of the inclusion

$$
\zeta=\frac{16 \pi a^{3}}{3 \omega^{3}}=\frac{\sqrt{2} \pi}{6} \approx 0,74 .
$$

This is a side-centered cubic structure. In this lattice the local symmetry in the stress condition is determined by the location of the nearest neighbors and equals to such symmetry that there is a simple cubic structure.

In hexagonal dense structure the basis of cell is formed by hexagonal grid (Fig. 2); the spheres centers are shifted so that the balls are located between the lying in the bottom surface. Each ball has six nearest neighbors in the main surface of the cell (as in a flat structure), but the other six neighbors are located in threes above and below the main surface.

The limiting packaging factor of environment is achieved when balls contact with each other:

$$
\zeta=\frac{8 \pi a^{3}}{3 \omega^{3} \sqrt{2}}=\frac{\pi}{3 \sqrt{2}} \approx 0,74 .
$$

In this case, the symmetry of the stress condition is characterized by the angle $\pi / 3$ in the main surface. It means we will receive the greatest changes during the rotation transformations. The comparison of considered spatial structures leads to the conclusion, that the simple cubic and hexagonal dense packings for the evaluation of dispersion boundaries of effective constants of composite environment have fundamental role. In a cubic lattice we have the lowest volumetric filling at the maximal approximation of inclusions, so with this structure the interaction between balls with equal volume content will be more

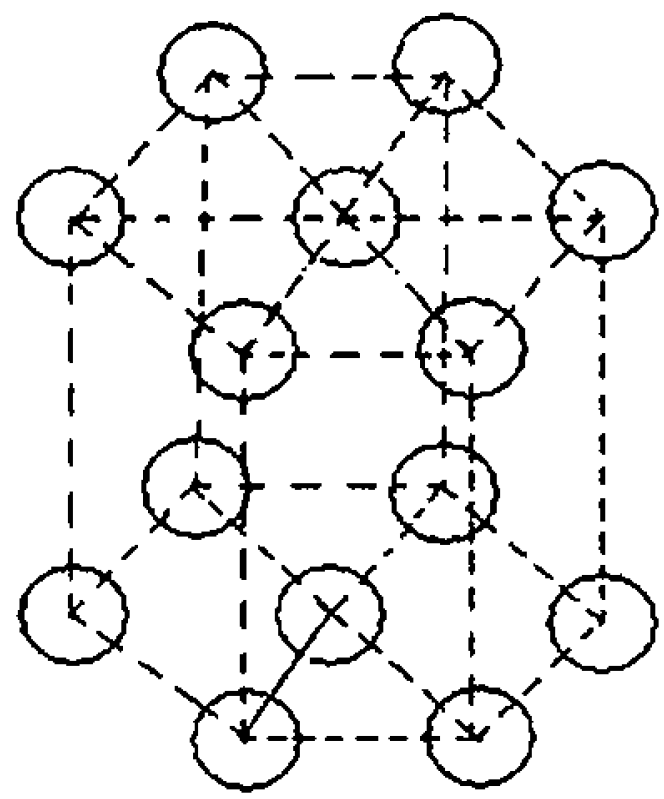

Fig. 2. The hexagonal dense structure.

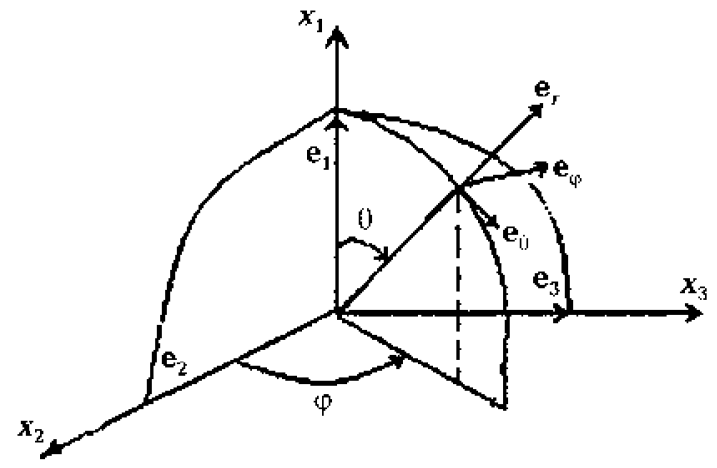

Fig. 3. System of spherical coordinates $r, \theta, \varphi$, relating to the interphase medium boundary. 
intense and similar to the interaction in the flat lattice. As the result of the symmetric environment the stress condition will be closest to the symmetric with respect to the various rotations in the hexagonal dense packing. Therefore in the first approximation, we can obtain elastic constants, that are closest in meaning to the hexagonal dense structure. The significant difference in the values of elastic constants is expected at the high filling condition.

We introduce a system of spherical coordinates $r, \theta, \varphi$, relating to the interphase boundary of environment (Fig. 3)

$$
x_{1}=r \cos \theta, \quad x_{2}=r \sin \theta \cos \varphi, \quad x_{3}=\sin \theta \sin \varphi, \quad 0 \leq r<\infty, \quad 0 \leq \theta \leq \pi, \quad 0 \leq \varphi \leq 2 \pi .
$$

The schedule of the orthogonal unit vectors on the sphere $\mathbf{e}_{1}, \mathbf{e}_{\theta}, \mathbf{e}_{\varphi}$, directed towards the growth in the spherical coordinates has the form

$$
\begin{gathered}
\mathbf{e}_{r}=\mathbf{e}_{1} \cos \theta+\mathbf{e}_{2} \sin \theta \cos \varphi+\mathbf{e}_{3} \sin \theta \sin \varphi \\
\mathbf{e}_{\theta}=-\mathbf{e}_{1} \sin \theta+\mathbf{e}_{2} \cos \theta \cos \varphi+\mathbf{e}_{3} \cos \theta \sin \varphi, \mathbf{e}_{\varphi}=-\mathbf{e}_{2} \sin \varphi+\mathbf{e}_{1} \cos \varphi .
\end{gathered}
$$

The first form of degree two and the square of the element on the surface of a sphere

$$
d s^{2}=d r^{2}+r^{2} d \theta^{2}+r^{2} \sin ^{2} \theta d \varphi^{2}, d f=r^{2} \sin \theta d \theta d \varphi .
$$

For isotropic inclusions and matrix in the approximation of a homogeneous interaction, we assume that the surrounding inclusion forms a hexagonal dense packing. In this structure effective properties do not depend on the chosen direction, so in the adopted approximation we direct the axis of $x_{1}$ and stress condition does not depend on the angle $\varphi$. Deformed axisymmetric condition in a spherical coordinate system is defined by components

$$
\begin{gathered}
\varepsilon_{r}=\frac{\partial u_{r}}{\partial r}, \quad \varepsilon_{r}=\frac{1}{r} \frac{\partial u_{\theta}}{\partial \theta}+\frac{1}{r} u_{r}, \varepsilon_{\varphi}=\frac{1}{r} u_{\theta} \operatorname{ctg} \theta+\frac{1}{r} u_{r}, \\
\gamma_{r \theta}=\frac{1}{r} \frac{\partial u_{r}}{\partial \theta}+\frac{\partial u_{\theta}}{\partial r}-\frac{1}{r} u_{\theta}, \Delta=\varepsilon_{r}+\varepsilon_{\theta}+\varepsilon_{\varphi},
\end{gathered}
$$

where $u_{r}, u_{\theta}, u_{\varphi}$ - are the components of displacement vector components of displacement vector

$$
\mathbf{u}=\mathbf{e}_{r} u_{r}+\mathbf{e}_{\theta} u_{\theta}+\mathbf{e}_{\varphi} u_{\varphi}
$$

Components of the stress tensor in spherical coordinate system

$$
\mathbf{T}=\mathbf{e}_{r} \mathbf{e}_{r} \sigma_{r}+\mathbf{e}_{\theta} \mathbf{e}_{\theta} \sigma_{\theta}+\mathbf{e}_{\varphi} \mathbf{e}_{\varphi} \sigma_{\varphi}+\left(e_{r} e_{\theta}+e_{\theta} e_{r}\right) \sigma_{r \theta} .
$$

Axisymmetrical stress condition. The task of the elasticity theory concerning the deformed axisymmetrical stress condition was reviewed by several authors [Sneddon, 1958; Christensen, 1979; Sirotin, 1975] so we write down the main results of it [Malezhyk, 2001]. Displacement vector components increasing with distance from the coordinates origin have such a form:

$$
\begin{gathered}
u_{r}^{(n)}=\left[A_{n} r^{n+1}(n+1)(n-2+4 v)+B_{n} n r^{n-1}\right] P_{n}(\cos \theta), \\
u_{\theta}^{(n)}\left[A_{n} r^{n+1}(n+5-4 v)+B_{n} n r^{n-1}\right] \frac{d P_{n}(\cos \theta)}{d \theta},
\end{gathered}
$$

the volume expansion

$$
\Delta^{n}=-2(1-2 v)(2 n+3)(n+1) A_{n} r^{n} P_{n}(\cos \theta),
$$


where $A_{n}, B_{n}$ - are the constants; $P_{n}(\cos \theta)$ - is $n$-th-order Legendre polynomial of the first kind, $n=$ $=1,2,3, \ldots$ The general solution with these components is

$$
U_{r}=\sum_{n=0}^{\infty} u_{r}^{(n)}, \quad U_{\theta}=\sum_{n=1}^{\infty} u_{\theta}^{(n)}, \Delta=\sum_{n=0}^{\infty} \Delta^{(n)} .
$$

Relevant components of the stress conditions are:

$$
\begin{aligned}
\sigma_{r}^{(n)}=2 G\left[A_{n}(n+1)\left(n^{2}-n-2-2 v\right) r^{n}+B_{n} n(n-1) r^{n-1}\right] P_{n}(\cos \theta), \\
\sigma_{r \theta}^{(n)}=2 G\left[A_{n}\left(n^{2}+2 n-1+2 v\right) r^{n}+B_{n}(n-1) r^{n-2}\right] \frac{P_{n}(\cos \theta)}{d \theta} \\
\sigma_{\theta}^{(n)}=-2 G\left[A_{n}\left(n^{2}+4 n+2+2 v\right)(n+1) r^{n}+B_{n} n^{2} r^{n-2}\right] P_{n}(\cos \theta)- \\
-2 G\left[A_{n}(n+5-4 v) r^{n}+B_{n} r^{n-2}\right] \frac{d P_{n}(\cos \theta)}{d \theta} \operatorname{ctg} \theta \\
\sigma_{\varphi}^{(n)}=2 G\left[A_{n}(n+1)(n-2-2 v-4 v) r^{n}+B_{n} n r^{n-2}\right] P_{n}(\cos \theta)+ \\
+2 G\left[A_{n}(n+5-4 v) r^{n}+B_{n} r^{n-2}\right] \frac{d P_{n}(\cos \theta)}{d \theta} \operatorname{ctg} \theta .
\end{aligned}
$$

The general stress condition is obtained by summing of the functions (12) for all $n$. Displacement vector components decreasing with the distance from the coordinates origin is presented in the form of

$$
\begin{gathered}
u_{r}^{(n)}=\left[\frac{C_{n}}{r^{n}} n(n+3-4 v)-\frac{D_{n}(n+1)}{r^{n+2}}\right] P_{n}(\cos \theta), \\
u_{r}^{(n)}=\left[\frac{C_{n}}{r^{n}}(-n+4-4 v)+\frac{D_{n}}{r^{n+2}}\right] \frac{d P_{n}(\cos \theta)}{d \theta} ;
\end{gathered}
$$

the volume expansion

$$
\Delta^{n}=-2(1-2 v)(2 n-1) n C_{n} r^{-(n+1)} P_{n}(\cos \theta) .
$$

Stress condition

$$
\begin{gathered}
\sigma_{r}=2 G\left[-\frac{C_{n} n}{r^{n+1}}\left(n^{2}+3 n-2 v\right)+\frac{D_{n}(n+1)(n+2)}{r^{n+3}}\right] P_{n}(\cos \theta), \\
\sigma_{r \theta}=2 G\left[-\frac{C_{n} n}{r^{n+1}}\left(n^{2}-2+2 v\right)-\frac{D_{n}(n+2)}{r^{n+3}}\right] \frac{d P_{n}(\cos \theta)}{d \theta},
\end{gathered}
$$




$$
\begin{aligned}
\sigma_{\theta}= & 2 G\left[\frac{C_{n} n}{r^{n+1}}\left(n^{2}-2 n-1+2 v\right)-\frac{D_{n}(n+1)^{2}}{r^{n+3}}\right] P_{n}(\cos \theta)- \\
& -2 G\left[\frac{C_{n} n}{r^{n+1}}(-n+4-4 v)+\frac{D_{n}}{r^{n+3}}\right] \frac{d P_{n}(\cos \theta)}{d \theta} \operatorname{ctg} \theta, \\
\sigma_{\varphi}= & 2 G\left[\frac{C_{n} n}{r^{n+1}}(n+2 n-4 n v-2 v)-\frac{D_{n}(n+1)}{r^{n+3}}\right] P_{n}(\cos \theta)+ \\
& +2 G\left[\frac{C_{n} n}{r^{n+1}}(-n+4-4 v)+\frac{D_{n}}{r^{n+3}}\right] \frac{d P_{n}(\cos \theta)}{d \theta} \operatorname{ctg} \theta,
\end{aligned}
$$

Perfect contact conditions of components when $r=a$

$$
u_{\theta}^{a}=u_{\theta}, \quad u_{r}^{a}=u_{r}, \quad \sigma_{r}^{a}=\sigma_{r}, \quad \sigma_{r \theta}^{a}=\sigma_{r \theta} .
$$

These conditions are supplemented by the stress conditions or deformations that characterize the interaction of homogeneous inclusions.

Environment with solid spherical inclusions. We consider the case when the spherical inclusion is in the unlimited isotropic environment that is affected by the uniform extension of the stress conditions at the distance of inclusion

$$
\sigma_{1}=\sigma_{2}=\sigma_{3}=\sigma^{0}
$$

where $\sigma^{0}-$ is an unknown uniform stress condition between inclusions.

The inclusion is connected with the environment, so the conditions (16) are performed on the interfaces. According to (10) and (12) in the spherical coordinate system (5), the origin of which coincides with the sphere center, the displacement and stress condition in the inclusion will be expressed by ratios

$$
\begin{gathered}
u_{r}^{a}=-2 B(1-2 v) \frac{3 k+4 G}{2 k_{a}+4 G} r, u_{\theta}^{a}=0, \\
\sigma_{r}^{a}=\sigma_{\theta}^{a}=\sigma_{\varphi}^{a}=-6 B(1-2 v) k_{a} \frac{3 k+4 G}{3 k_{a}+4 G} r, \sigma_{r \theta}^{a}=0,
\end{gathered}
$$

According to (13) and (15) the condition of the environment is

$$
\begin{gathered}
u_{r}=-2(1-2 v) B^{\prime}+6(1-2 v) \frac{k_{a}-k}{3 k_{a}+4 G} B \frac{a^{3}}{r^{2}}, u_{\theta}=0, \\
\sigma_{r}=-2 E B-24 G(1-2 v) \frac{k_{a}-k}{3 k_{a}+4 G} B \frac{a^{3}}{r^{3}}, \\
\sigma_{\theta}=\sigma_{\varphi}=-2 E B+12 G(1-2 v) \frac{k_{a}-k}{3 k_{a}+4 G} B \frac{a^{3}}{r^{3}}, \sigma_{r \theta}=0 .
\end{gathered}
$$

In terms of the isotropic solid uniform extension the elastic energy is expressed by the surface integral. By the deformation of the surface $\mathrm{S}_{0}$ into the concentric isometric sphere with radius $R$, we obtain 


$$
U=\frac{1}{2 v} \int_{S_{0}} \sigma_{r} \Gamma_{r} R^{2} \sin \theta d \theta d \varphi=\frac{3}{2}\langle\sigma\rangle\langle\varepsilon\rangle
$$

Under the uniform extension of stress conditions $\langle\sigma\rangle$ the average deformation of isotropic environment is

$$
\left\langle\varepsilon_{1}\right\rangle=\left\langle\varepsilon_{2}\right\rangle=\left\langle\varepsilon_{3}\right\rangle=\langle\varepsilon\rangle=\frac{\langle\sigma\rangle}{3 K_{0}},
$$

where $K_{0}$ is the effective volume modulus of the compositional environment. The radial displacement can be expressed by the average deformations

$$
u_{r}=\left(\mathbf{e}_{1} \mathbf{e}_{r}\right) u_{1}+\left(\mathbf{e}_{2} \mathbf{e}_{r}\right) u_{2}+\left(\mathbf{e}_{3} \mathbf{e}_{r}\right) u_{3}=\langle\varepsilon\rangle r\left(u_{1} \cos \theta+u_{2} \sin \theta \cos \varphi+u_{3} \sin \theta \cos \varphi\right) .
$$

The calculation of the integral using of the first energy representation (20) leads to the formula

$$
B=-\frac{\langle\sigma\rangle}{6(1-2 v)} \frac{3 k_{a}+4 G}{3 k_{a} k+4 \zeta G k_{a}+4(1-\zeta) G k} .
$$

The ratios (17) and (19) allow you us to find the stress condition between the inclusions

$$
\sigma^{0}=\frac{k\left(3 k_{0}+4 G\right)\langle\sigma\rangle}{3 k_{a} k+4 \zeta G k_{a}+4(1-\zeta) G k} .
$$

The volume modulus is determined by replacing the right side of equation (20) to another energy supply and stress conditions $\sigma_{r}$ on the average values in the integrand function

where

$$
\sigma_{r}=\mathbf{e}_{r} \cdot \mathbf{e}_{r} \cdot \mathbf{T}=\sigma,
$$

$$
\mathbf{T}=\left(\mathbf{e}_{1} \mathbf{e}_{1}+\mathbf{e}_{2} \mathbf{e}_{2}+\mathbf{e}_{3} \mathbf{e}_{3}\right)\langle\sigma\rangle,
$$

the next part

$$
\frac{\langle\sigma\rangle^{2}}{2 K_{0}}+\frac{\langle\sigma\rangle}{2 v} \int_{0}^{n} \int_{0}^{2 n} u_{r} R^{2} \sin \theta d \theta d \varphi=-\frac{\langle\sigma\rangle^{2}}{2} \frac{3 \zeta k+3(1-\zeta) k_{a}+4 G}{3 k_{a} k+4 \zeta G k_{a}+4(1-\zeta) G k}
$$

According to this the effective modulus of volume elasticity is

$$
K_{0}=\frac{3 k_{a} k+4 G \zeta k_{a}+4(1-\zeta) G k}{3(1-\zeta) k_{a}+3 \zeta k+4 G}
$$

Note that this ratio was obtained in a slightly different way [Malezhyk, 2001].

To determine the second constant of the elasticity we find Young's modulus in terms of simple stretching of the compositional environment along the axis $\mathrm{O} x_{1}$. We accept functions (10) and (12) as the acceptable solutions for inclusion. The state of the environment between inclusions is determined by the solutions (13) and (15), that are complemented by a function that characterizes the homogeneous interaction of inclusions. We fulfill the perfect contact conditions (16) and find them for inclusion

$$
u_{r}^{a}=\frac{1}{9 k} \frac{3 k+4 G}{3 k_{a}+4 G} Q r+\frac{5(1-v)}{(7-5 v) G+(8-10 v) G_{a}} Q r P_{2}(\cos \theta),
$$




$$
\begin{aligned}
& u_{\theta}^{a}=\frac{5}{2} \frac{1-v}{(7-5 v) G+(8-10 v) G_{a}} Q r \frac{d P_{2}(\cos \theta)}{d \theta} \\
& \sigma_{r}^{a}=\frac{k_{a}}{3 k} \frac{3 k+4 G}{3 k_{a}+4 G} Q+\frac{10(1-v) G_{a}}{(7-5 v) G+(8-10 v) G_{a}} Q P_{2}(\cos \theta), \\
& \sigma_{r \theta}^{a}=\frac{5(1-v) G_{a}}{(7-5 v) G+(8-10 v) G_{a}} Q \frac{d P_{2}(\cos \theta)}{d \theta} \\
& \sigma_{\theta}^{a}=\frac{k_{a}}{3 k} \frac{3 k+4 G}{3 k_{a}+4 G} Q-\frac{5(1-v) G_{a}}{(7-5 v) G+(8-10 v) G_{a}} Q\left[4 P_{2}(\cos \theta)+\frac{d P_{2}(\cos \theta)}{d \theta} \operatorname{ctg} \theta\right], \\
& \sigma_{\varphi}^{a}=\frac{k_{a}}{3 k} \frac{3 k+4 G}{3 k_{a}+4 G} Q+\frac{5(1-v) G_{a}}{(7-5 v) G+(8-10 v) G_{a}} Q\left[2 P_{2}(\cos \theta)+\frac{d P_{2}(\cos \theta)}{d \theta} \operatorname{ctg} \theta\right]
\end{aligned}
$$

for the environment between the inclusions

$$
\begin{aligned}
& u_{r}=\frac{1}{9 k} Q r-\frac{1}{3 k} \frac{k_{a}-k}{3 k_{a}+4 G} Q \frac{a^{3}}{r^{2}}+\left[\frac{1}{3 G} r+\frac{10-8 v}{12 G} \frac{5\left(G-G_{a}\right)}{(7-5 v) G+(8-10 v) G_{a}} \frac{a^{3}}{r^{2}}-\right. \\
& \left.-\frac{3}{2 G} \frac{G-G_{a}}{(7-5 v) G+(8-10 v) G_{a}} \frac{a^{5}}{r^{4}}\right] Q P_{2}(\cos \theta) \text {, } \\
& u_{\theta}=\left[\frac{1}{3} r+\frac{5}{3} \frac{(1-2 v)\left(G-G_{a}\right)}{(7-5 v) G+(8-10 v) G_{a}} \frac{a^{3}}{r^{2}}+\right. \\
& \left.+\frac{G-G_{a}}{(7-5 v) G+(8-10 v) G_{a}} \frac{a^{5}}{r^{4}}\right] \frac{Q}{2 G} \frac{d P_{2}(\cos \theta)}{d \theta}, \\
& \sigma_{r}=\frac{1}{3} Q=\frac{4 G}{3 k} \frac{k_{a}-k}{3 k_{a}+4 G} Q \frac{a^{3}}{r^{3}}+\left[\frac{2}{3}-\frac{5}{3} \frac{(10-2 v)\left(G-G_{a}\right)}{(7-5 v) G+(8-10 v) G_{a}} \frac{a^{3}}{r^{3}}+\right. \\
& \left.+\frac{12\left(G-G_{a}\right)}{(7-5 v) G+(8-10 v) G_{a}} \frac{a^{5}}{r^{3}}\right] Q P_{2}(\cos \theta) \\
& \sigma_{r \theta}=\left[\frac{1}{3}+\frac{5}{3} \frac{(1+v)\left(G-G_{a}\right)}{(7-5 v) G+(8-10 v) G_{a}} \frac{a^{3}}{r^{3}}-\right.
\end{aligned}
$$




$$
\begin{aligned}
& \left.-\frac{4\left(G-G_{a}\right)}{(7-5 v) G+(8-10 v) G_{a}} \frac{a^{5}}{r^{5}}\right] Q \frac{d P_{2}(\cos \theta)}{d \theta} \\
& \sigma_{\theta}=\frac{2}{3} Q-\frac{2 G}{3 k} \frac{k_{a}-k}{3 k_{a}+4 G} \frac{a^{3}}{r^{3}} Q-\left[\frac{2}{3}+\frac{5}{3} \frac{(1-2 v)\left(G-G_{a}\right)}{(7-5 v) G+(8-10 v) G_{a}} \times\right. \\
& \left.\times \frac{a^{3}}{r^{3}}+\frac{9\left(G-G_{a}\right)}{(7-5 v) G+(8-10 v) G_{a}} \frac{a^{5}}{r^{5}}\right] Q P_{2}(\cos \theta)- \\
& -\left[\frac{5}{3}(1-2 v) \frac{a^{3}}{r^{3}}+\frac{a^{5}}{r^{5}}\right] \frac{\left(G-G_{a}\right)}{(7-5 v) G+(8-10 v) G_{a}} Q \frac{d P_{2}(\cos \theta)}{d \theta} \operatorname{ctg} \theta, \\
& \sigma_{\varphi}=-\frac{2 G}{3 k} \frac{k_{a}-k}{3 k_{a}+4 G} Q \frac{a^{3}}{r^{3}}+\left[\frac{5}{3}(5-8 v) \frac{a^{3}}{r^{3}}-3 \frac{a^{5}}{r^{5}}\right] \times \\
& \times \frac{G-G_{a}}{(7-5 v) G+(8-10 v) G_{a}} Q P_{2}(\cos \theta)+\left[\frac{5}{3}(1-2 v) \frac{a^{3}}{r^{3}}+\frac{a^{5}}{r^{5}}\right] \times \\
& \times \frac{G-G_{a}}{(7-5 v) G+(8-10 v) G_{a}} \frac{d P_{2}(\cos \theta)}{d \theta} \operatorname{ctg} \theta .
\end{aligned}
$$

We find the constant $Q$ according to the first energy representation

$$
\frac{1}{2 v} \int_{S_{\theta}}\left(\sigma_{r} u_{r}+\sigma_{r \theta} u_{\theta}\right) r^{2} \sin \theta d \theta d \varphi=\frac{1}{2}\left\langle\sigma_{1}\right\rangle\left\langle\varepsilon_{1}\right\rangle
$$

where $u_{r}=\left\langle\varepsilon_{1}\right\rangle r \cos ^{2} \theta ; u_{\theta}=-\left\langle\varepsilon_{1}\right\rangle r \cos \theta \sin \theta ; u_{\varphi}=0$.

The coherence between the internal field and the average stress

$$
Q=\frac{\left\langle\sigma_{1}\right\rangle}{1+\frac{4 \zeta G}{3 k} \frac{k_{a}-k}{3 k_{a}+4 G}+\frac{2 \zeta}{3} \frac{(7-5 v)\left(G_{a}-G\right)}{(7-5 v) G+(8-10 v) G_{a}}}
$$

The elasticity modulus of environment is determined by the substitution of another energy representation in the right part (24) under the integral we consider

$$
\sigma_{r}=\left\langle\sigma_{1}\right\rangle \cos ^{2} \theta, \quad \sigma_{r \theta}=-\left\langle\sigma_{1}\right\rangle \cos \theta \sin \theta .
$$

write down the formula

$$
E_{0}=E \frac{1+\frac{4 \zeta G}{3 k} \frac{k_{a}-k}{3 k_{a}+4 G}+\frac{2 \zeta}{3} \frac{(7-5 v)\left(G_{a}-G\right)}{(7-5 v) G+(8-10 v) G_{a}}}{1-\frac{\zeta E}{3 k} \frac{k_{a}-k}{3 k_{a}+4 G}-\frac{2 \zeta E}{3 G} \frac{(4-5 v)\left(G_{a}-G\right)}{(7-5 v) G+(8-10 v) G_{a}}}
$$


In the adopted approximation effective constants $K_{0}, E_{0}$ allow us to find other environment characteristics:

$$
v_{0}=\frac{1}{2}-\frac{E_{0}}{6 K_{0}}, G_{0}=\frac{E_{0}}{3-\frac{E_{0}}{K_{0}}} .
$$

The calculation data of the elastic constants environment is shown in Fig. 4, where hatched curve 4 determines the change $v_{0}$ with increasing volume content of $\zeta$ (upper scale) and curves $1-3$ are calculated according to $l-K_{0} / K, 2-E_{0} / E, 3-$ $G_{0} / G$ (lower scale). The calculations are carried out in relation to the composite environment of epoxide as matrix and glass solid spheres (as inclusion) with features: $v=0,38 ; v_{0}=0,2 ; G_{0} / G=25$.

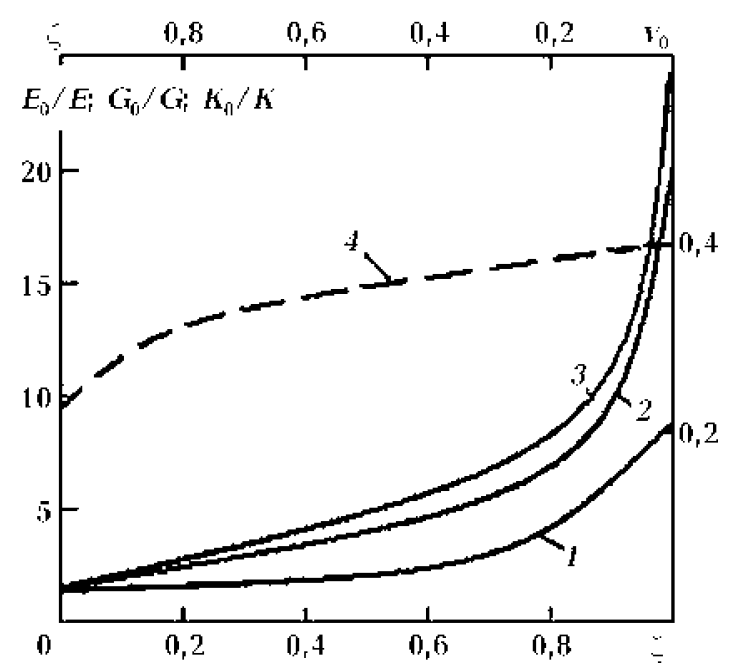

Fig. 4. The calculation data of complete set of the environmental elastic constants.

Under conditions of identical spheres, the limit value of the volume content (see (1) and (3)) is

$$
0,52 \leq \zeta_{\max } \leq 0,74 \text {. }
$$

Close to the specified values $E_{0}, K_{0}$ value significantly deviate from accurate values. It depends on the package. The application area of ratios (21) and (27) will be higher for hexagonal packing. In this approximation stress concentration at the interface decreases with increasing of volume content of spheres, which indicates the fidelity of the solution only for small $\zeta$.

To obtain the upper estimates of the effective elastic constants in the approximation of the uniform interaction in the determination of the constant $Q(24)$ it is necessary to accept the formula

$$
u_{r}=\left\langle\varepsilon_{1}\right\rangle r\left(\cos ^{2} \theta-v \sin ^{2} \theta\right), u_{\theta}=\left\langle\varepsilon_{1}\right\rangle r(1+v) \sin \theta \cos \theta .
$$

This substitution leads to the following coherence of $Q$ with the average stress condition:

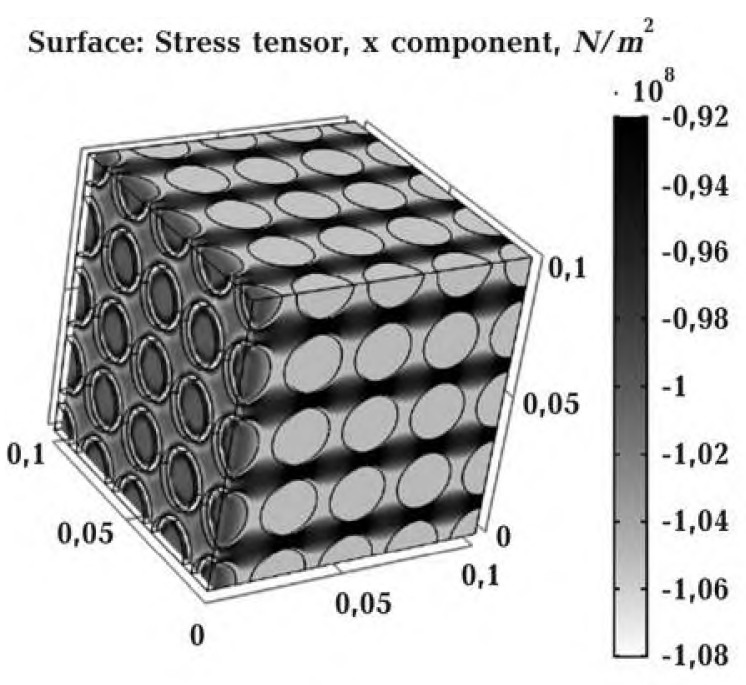

a

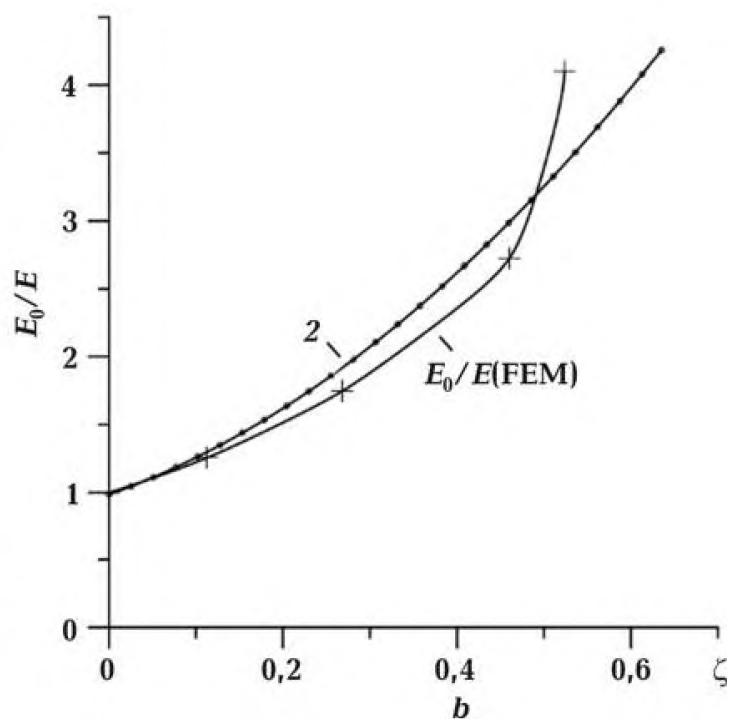

b

Fig. 5. The results comparison the numerical simulation of a structured environment compression with an analytic solution (27): $a-\mathrm{x}$-component of stress tensor $\sigma_{x x}$ in uniaxial-compressed medium along $\mathrm{x}$ direction, $b-2$-analytic solution $(27)$, (FEM) - digital solution. 


$$
Q=\frac{\left\langle\sigma_{1}\right\rangle}{1+\frac{4 \zeta G}{3 k} \frac{(1-2 v) k_{a}-k}{3 k_{a}+4 G}+\frac{2 \zeta}{3} \frac{(1+2 v)(7-5 v)\left(G_{a}-G\right)}{(7-5 v) G+(8-10 v) G_{a}}} .
$$

In this case, the formula for the module (27) takes the form:

$$
E_{0}=E \frac{1+\frac{4 \zeta G}{3 k} \frac{(1-2 v) k_{a}-k}{3 k_{a}+4 G}+\frac{2 \zeta}{3} \frac{(1+2 v)(7-5 v)\left(G_{a}-G\right)}{(7-5 v) G+(8-10 v) G_{a}}}{1-\frac{\zeta E}{3 k} \frac{k_{a}-k}{3 k_{a}+4 G}-\frac{2 \zeta}{3 G} \frac{(4-5 v)\left(G_{a}-G\right)}{(7-5 v) G+(8-10 v) G_{a}}}
$$

The values of the effective constants obtained by this formula are a few percent higher than other
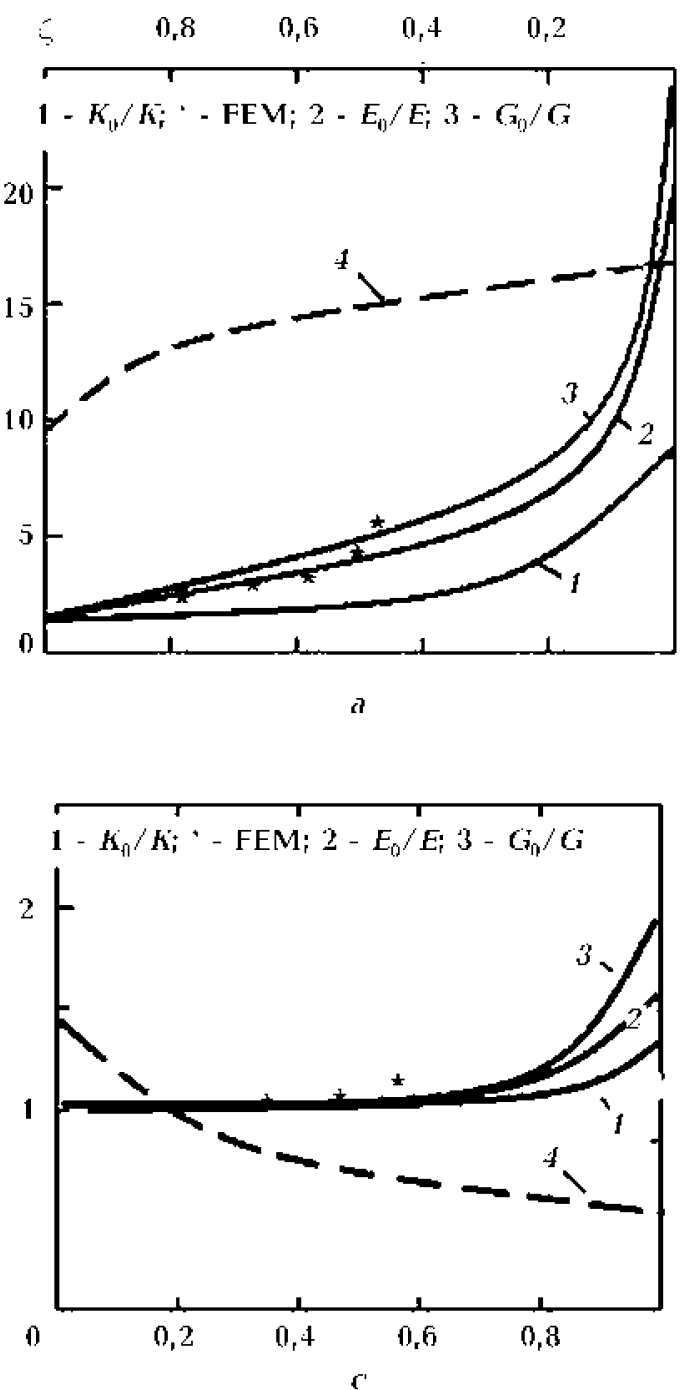

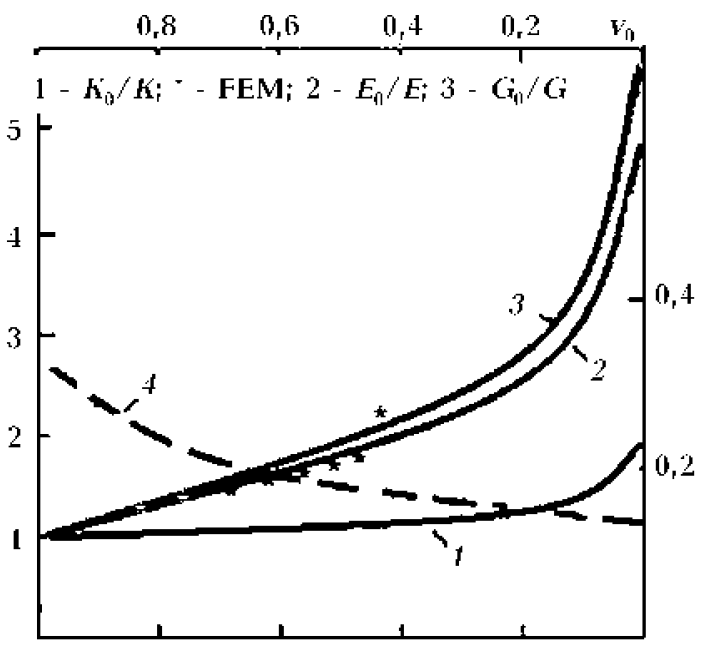

b

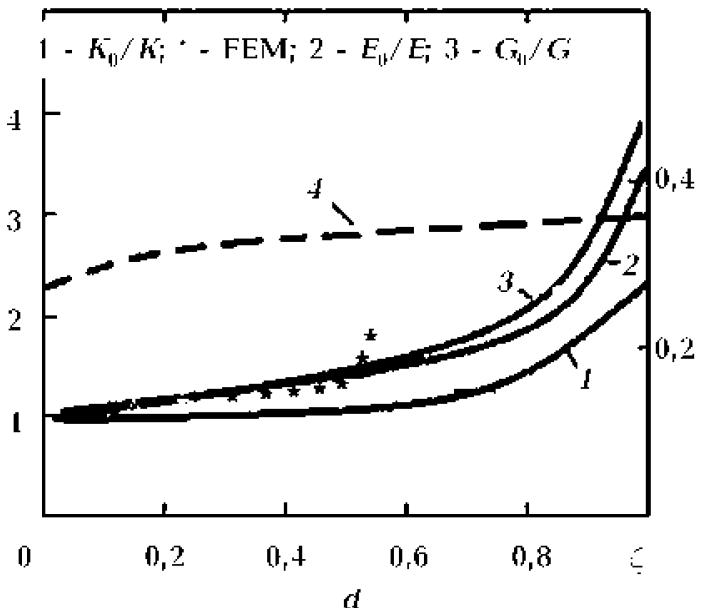

Fig. 6. The calculation data of complete set of the environmental elastic constants for: $a$ - epoxide as matrix and glass solid grain; $b$ - shale clays as matrix and granite spheres; $c$ - shale clays as matrix and sandstone spheres; $d$ - sandstone as matrix and dranite spheres; * - FEM modelling for curve 2. 
constants founded by the ratios (21) and (27). The formulas for the elastic modulus or shift [Lure, 1955] are highly approximate because they assume linear dependence of the effective modules from the parameter $\zeta$.

The calculation data (based on 31) of the elastic constants for some few another types of media is shown in Fig. 6, where hatched curve 4 determines the change $v_{0}$ with increasing volume content of $\zeta$ (upper scale) and curves $1-3$ are calculated according to $1-K_{0} / K, 2-E_{0} / E, 3-G_{0} / G$ (lower scale). Fig. 6, $a$ shows: the calculations are carried out in relation to the composite environment of epoxide as matrix and glass solid spheres (as inclusion) with features: $v=0,38 ; v_{a}=0,2 ; G_{a} / G=25$. Fig. $6, b$ shows: the calculations are carried out in relation to the composite environment of shale clays as matrix and granite spheres: $v=0,15 ; v_{a}=0,29 ; G_{a} / G=6$. Fig. $6, c$ shows: the calculations are carried out in relation to the composite environment of shale clays as matrix and sandstone spheres : $v=0,15 ; v_{a}=0,35$; $G_{a} / G=1,7$. Fig. $6, d$ shows: the calculations are carried out in relation to the composite environment of sandstone as matrix and dranite spheres: $v=0,35 ; v_{a}=0,29 ; G_{a} / G=3,5$. Stars represent values of elastic constants resulting on numerical simulations of compression of the respective environments.

Conclusions. As you are well aware the geological sciences analyze environment patterns with very complex structure and composition. That is why we consider often the behavior of such materials from the point of view of their averaged characteristics. As well as often we are good with the modelling of the elastic behavior of structured geophysical media, thus it is important to determine elastic constants of such model environments. The used in this paper method of averaging to study the state of composite media differs from the universally accepted approach when the stress and strain are averaged by volume. In this case, the effective elasticity modules theory is based on determining of the relative volumetric filling of an environment with particles, and the averaging method is based on the dominant elements concordance in the decomposition of particular exact solution for bodies with periodic structures at the model's interfaces. Using this approach we have derived the analytical formulas $(27,28,31)$ for all important elastic constants of such composite materials. Then we have made numerical modelling of similar composite materials compression processes using the finite element method and have calculated the same constants.

The comparison of results shows that analytical solutions are satisfactory for all materials up to large coefficients of the volume content of the model. With large ones $(\zeta>0,5)$, there are raised differences there. This is an explained deviation since in this case by the numerical solution we find the initiation of yielding (see stress concentration in Fig. 5,a). 


\title{
Mathematical modelling of the elastic behavior of structured geophysical media
}

\author{
(C) N. V. Olali, D. B. Vengrovich, M. P. Malezhyk, 2017
}

From the viewpoint of modern concepts of nonlinear geophysics, the presence of the hierarchical block structure, anisotropy and heterogeneities is the defining property of the natural medium in particular of the Earth's crust. A lot of achievements of modern self-organization theory in geophysics are based on the existence of basic structured media models. The structure plays a key role in Earth's crust dynamic that is important for tectonic stress origin and localization as well as for next stress-relieved processes. As shown in [Starostenko et al., 2001], it is necessary to describe such a structured media at the micro-, meso- and macro-level as a sets of interacting blocks. Mathematical models created in such a way in particular numerical models of the dynamics of block-structured lithosphere allow us to describe reliably such tectonic processes as the formation and evolution of the rift sedimentary basins [Starostenko et al., 2001], Earth's crust compression in the subduction zones [Vengrovich, 2017], or faster tectonic processes of halo kinesis [Vengrovich, 2010]. The mechanism of local accumulation and emission of energy in the seismic waves form, which could be a way of creating a new model of earthquake source, was revealed during the investigation of rifting [Starostenko et al., 1996] and new subduction process modelling in the frame of block-structured lithosphere theory. However tectonic and seismic processes go far beyond the spatial and temporal scales. Used approaches need to be implemented in numerous models on the micro and mesolevel where it is extremely costly to calculate the dynamics of a huge number of interacting blocks. Therefore, we propose the mathematical model of the elastic behavior of the structured geophysical media allowing to obtain analytical dependencies between its elastic parameters and structure. We describe such environment in the first approximation as an elastic solid matrix with the inclusions of granules with excellent rheological properties. As usual rock formations keep irregular positions of particles different shapes and sizes in the space. These particles can be separated from the binder by fracturing. However, in this paper, we neglect nonregularity, fracturings, cap it all the granules will be considered as spherical. We combined the optical method of photo-elasticity studies [Malezhyk, 2001; Sirotin, Shaskolskaja, 1975; Sneddon, 1958; Christensen, 1979] and numerical calculations (FEM model) of stress fields dynamic in structured media using finite element analysis, overall, in such a way the proposed analytical model will be proofed. The numerical and analytical calculations of the stress fields evolution in the real earth with an internal structure are presented.

Key words: stress field, geophysical media, structure, crust, elastic moduli.

\section{References}

Christensen R. M., 1979. Mechanics of composite materials. New York; Wiley-Interscience, 348 p.

Lure A. I., 1955. The spatial tasks of the elasticity theory. Moscow: Gostekhizdat, 492 p. (in Russian).

Malezhyk M. P., 2001. Dynamic photo-elasticity of anisotropic bodies. Kiev: IGP NASU, 200 p. (in Russian).

Sirotin Yu. I., Shaskolskaja M. P., 1975. The basics of crystal physics. Moscow: Nauka, 680 p. (in Russian).

Sneddon J. N., Berry D. S., 1958. The classical theory of elasticity. (Handbuch der physik herausg. von. S. Flugge. Bd. 6. Elastizität und Plastizität). Berlin u. a., Springer-Verl.

Starostenko V. I., Danilenko V. A., Vengrovich D. B., Poplavskii K. N., 1996. A fully dynamic model of continental rifting applied to the syn-rift evolution of sedimentary basins. Tectonophysics 268(1), 211-220.

Starostenko V. I., Danilenko V. A., Vengrovich D. B., Kutas R. I., Stovba S. M., Stephenson R., 2001. Modeling of the Evolution of Sedimentary Basins Including the Structure of the Natural Medium and Self-Organization Processes. Izvestiya, Physics of the Solid Earth 37(12), 1004-1014.

Vengrovich D. B., 2010.Computer simulation related to salt tectonics in the Dnieper-Donets basin. Geofizicheskiy zhurnal 32(4), $198-200$.

Vengrovich D. B., 2017. Seismicity of rifting and subduction. Vesnik Khersonskogo Natsionalnogo Tekhnicheskogo Universiteta 3(62), 60-65. 